\title{
Electronic structure and luminescence properties of $\mathrm{BaSi}_{2} \mathrm{O}_{2} \mathrm{~N}_{2}: \mathrm{Eu}^{2+}$ phosphor for white LEDs
}

\author{
Huayan Pan ${ }^{1, a}$,Dong Luo ${ }^{2, b}$, Le Wang ${ }^{3, c}$, Yanghui $\mathrm{Li}^{4, \mathrm{~d}}$ \\ ${ }^{1,2,3,4}$ Laboratory of Optoelectronic Materials and Devices,College of Optics and Electronic Science \\ and Technology, China Jiliang University, Hangzhou, China \\ a1443515959@qq.com, ${ }^{\text {b } 1018643275 @ q q . c o m, ~}{ }^{\mathrm{c}}$ calla@cjlu.edu.cn, ${ }^{\mathrm{d}} 502826199 @$ qq.com
}

Keywords: Oxynitride phosphor; Precursor method; White LEDs; Photoluminescence Abstract. Bluish-green $\mathrm{BaSi}_{2} \mathrm{O}_{2} \mathrm{~N}_{2}: \mathrm{Eu}^{2+}$ phosphors were synthesized by a method using $\mathrm{Ba}_{2} \mathrm{SiO}_{4}$ as a precursor. The luminescence properties and formation process of $\mathrm{BaSi}_{2} \mathrm{O}_{2} \mathrm{~N}_{2}$ : $\mathrm{Eu}^{2+}$ phosphors formed by the method at varied $\mathrm{Eu}^{2+}$ concentrations and varied temperatures were investigated by $\mathrm{X}$-ray diffraction (XRD), fluorescence spectrometer photometer (PL) and scanning electron microscope (SEM) respectively. Compared with a conventional solid-state reaction method, this method provided increased crystallinity and luminescence efficiency. A single phase of $\mathrm{BaSi}_{2} \mathrm{O}_{2} \mathrm{~N}_{2}: \mathrm{Eu}^{2+}$ was formed in the precursor method. Under $330 \mathrm{~nm}$ excitation, the $\mathrm{BaSi}_{2} \mathrm{O}_{2} \mathrm{~N}_{2}: \mathrm{Eu}^{2+}$ phosphors showed a broad emission band with a peak of $498 \mathrm{~nm}$ for varied $\mathrm{Eu}^{2+}$ concentrations and showed the maximum emission peak intensity when $\mathrm{Eu}^{2+}$ doping amount was $4 \%$. These excellent luminescence properties suggested that $\mathrm{BaSi}_{2} \mathrm{O}_{2} \mathrm{~N}_{2}: \mathrm{Eu}^{2+}$ is an excellent phosphor for white LEDs.

\section{Introduction}

Nowadays, white light-emitting diodes (LEDs) are expected to be next generation white light source due to their promising advantages such as lower energy consumption, long lifetime, high reliability, environmental protection and so on ${ }^{[1,2]}$. The white LEDs composed of blue GaInN LED and yellow phosphor (such as YAG: $\mathrm{Ce}^{3+}$ ) shows a poor color rendering index due to the lack of red light component. In order to achieve this disadvantage, available white LEDs are mostly using tri-colored phosphor (red, green and blue) excited by a near ultraviolet chip currently ${ }^{[3-5]}$. This phosphor shows high luminescence efficiency and high chemical stability and low color rendering index. However, diverse requirements are made on phosphors, higher efficiency and higher color rendering index.

In recent years, some oxynitride phosphors were reported to be promising luminescence phosphors for white LED applications because of their outstanding chemical, thermal, mechanical stability and good luminescence properties. Such as $\mathrm{MSi}_{2} \mathrm{O}_{2} \mathrm{~N}_{2}(\mathrm{M}=\mathrm{Ca}, \mathrm{Sr}, \mathrm{Ba})^{[6-8]}, \mathrm{SiAlON}^{[9]}$, $\mathrm{M}_{2} \mathrm{Si}_{5} \mathrm{~N}_{8}(\mathrm{M}=\mathrm{Ca}, \mathrm{Sr}, \mathrm{Ba})^{[10-12]}$. However, synthesis of these phosphors, requires high-temperature, high-pressure and reducing environment. Among these oxynitride phosphors, $\mathrm{MSi}_{2} \mathrm{O}_{2} \mathrm{~N}_{2}: \mathrm{Eu}^{2+}(\mathrm{M}=$ $\mathrm{Ca}, \mathrm{Sr}, \mathrm{Ba}$ ) phosphors have recently attracted much attention as promising phosphors for white LED lighting due to their relatively lower sythesized tempretures, outstanding luminescence properties, high thermal and chemical stability ${ }^{[13-15]}$. These phosphors are layer structure made by the $\mathrm{Si}(\mathrm{O}, \mathrm{N})_{4}$ oxygen nitrogen tetrahedron or $\mathrm{SiN}_{4}$ pure nitrogen tetrahedron. Particularly, the Ba base material $\left(\mathrm{BaSi}_{2} \mathrm{O}_{2} \mathrm{~N}_{2}: \mathrm{Eu}^{2+}\right)$ has the most excellent luminous efficiency and excitation intensity. In recent years, $\mathrm{Eu}^{2+}$-doped $\mathrm{BaSi}_{2} \mathrm{O}_{2} \mathrm{~N}_{2}$ phosphor was reported by many workers. This material is expected to be a very promising green-yellow emitting phosphor for application to white LEDs because of high quantum efficiency and low thermal quenching of luminescence. However, $\mathrm{BaSi}_{2} \mathrm{O}_{2} \mathrm{~N}_{2}: \mathrm{Eu}^{2+}$ turned out that it was difficult to obtain a pure-phase.

In this work, $\mathrm{BaSi}_{2} \mathrm{O}_{2} \mathrm{~N}_{2}$ : $\mathrm{Eu}^{2+}$ phosphor was prepared by a method using $\mathrm{Ba}_{2} \mathrm{SiO}_{4}$ as a precursor, and luminescence properties of this phosphor was investigated. The formation process of $\mathrm{BaSi}_{2} \mathrm{O}_{2} \mathrm{~N}_{2}$ : $\mathrm{Eu}^{2+}$ was also investigated through observation of phase types and luminescence properties of samples formed by the method at varied $\mathrm{Eu}^{2+}$ concentrations and varied temperatures. A 
single phase of $\mathrm{BaSi}_{2} \mathrm{O}_{2} \mathrm{~N}_{2}: \mathrm{Eu}^{2+}$ was formed in the precursor method. Under $330 \mathrm{~nm}$ excitation, the $\mathrm{BaSi}_{2} \mathrm{O}_{2} \mathrm{~N}_{2}: \mathrm{Eu}^{2+}$ phosphors showed a broad emission band with a peak of $498 \mathrm{~nm}$ for varied $\mathrm{Eu}^{2+}$ concentrations and showed the maximum emission peak intensity when $\mathrm{Eu}^{2+}$ doping amount was $4 \%$.

\section{Experimental}

$\mathrm{BaSi}_{2} \mathrm{O}_{2} \mathrm{~N}_{2}: \mathrm{Eu}^{2+}$ samples were synthesized using solid-state reaction method and precursor method. For the solid-state reaction method, a stoichiometric mixture of $\mathrm{BaCO}_{3}(99.9 \%), \mathrm{SiO}_{2}(99.9 \%), \mathrm{Si}_{3} \mathrm{~N}_{4}$ (99.9\%) and $\mathrm{Eu}_{2} \mathrm{O}_{3}(99.9 \%)$ was fired at $1400{ }^{\circ} \mathrm{C}{ }^{\circ} \mathrm{C}$ for $5 \mathrm{~h}$ under a reducing atmosphere of $\mathrm{H}_{2}(5 \%)-\mathrm{N}_{2}(95 \%)$ in a tube furnace. For the precursor method, a mixture of $\mathrm{BaCO}_{3}(99.9 \%)$, $\mathrm{SiO}_{2}(99.9 \%)$ was fired under a reducing gas flow at $1200^{\circ} \mathrm{C}^{\circ} \mathrm{C}$ for $5 \mathrm{~h}$ to produce $\mathrm{Ba}_{2} \mathrm{SiO}_{4} \mathrm{samples}$. Then, a mixture of $\mathrm{Si}_{3} \mathrm{~N}_{4}, \mathrm{Eu}_{2} \mathrm{O}_{3}$ and the $\mathrm{Ba}_{2} \mathrm{SiO}_{4}$ sample was fired again at $1400^{\circ} \mathrm{C}{ }^{\circ} \mathrm{C}$ for $5 \mathrm{~h}$ in the same reducing atmosphere to synthesize $\mathrm{BaSi}_{2} \mathrm{O}_{2} \mathrm{~N}_{2}: \mathrm{Eu}^{2+}$ phosphor. $\mathrm{Eu}^{2+}$ concentration with respect to $\mathrm{BaSi}_{2} \mathrm{O}_{2} \mathrm{~N}_{2}: \mathrm{Eu}^{2+}$ was varied from 0 to $8 \%$.

The obtained samples were characterized by XRD (Bruker D2 PHASER, Germany) with Cu Ko radiation $(\lambda=0.15406 \mathrm{~nm})$ operating at $30 \mathrm{kV}$ and $10 \mathrm{~mA}$. The data were collected by a step width of $0.02^{\circ}$ and a scan range of $10^{\circ} \sim 80^{\circ}$. Photo-luminescence spectra were measured using a fluorescence spectrometer (HORIBA Jobin Yvon Fluorolog) at room temperature.

\section{Results and discussion}

Fig. 1 shows the XRD patterns of $\mathrm{BaSi}_{2} \mathrm{O}_{2} \mathrm{~N}_{2}: \mathrm{Eu}^{2+}$ phosphors prepared by different methods. Both samples were fired at $1400^{\circ} \mathrm{C}^{\circ} \mathrm{C}$ and doped with $4 \% \mathrm{Eu}^{2+}$. This result shows that the sample prepared by solid-state reaction method (a) includes an impurity phase $\left({ }^{*} \mathrm{Ba}_{2} \mathrm{SiO}_{4}\right)$. All of the observed peaks of the sample prepared by precursor method (b) matched well with those of calculated XRD pattern of $\mathrm{BaSi}_{2} \mathrm{O}_{2} \mathrm{~N}_{2}$ (c), indicating that a single phase of $\mathrm{BaSi}_{2} \mathrm{O}_{2} \mathrm{~N}_{2}$ was obtained by the sample prepared by precursor method (b).

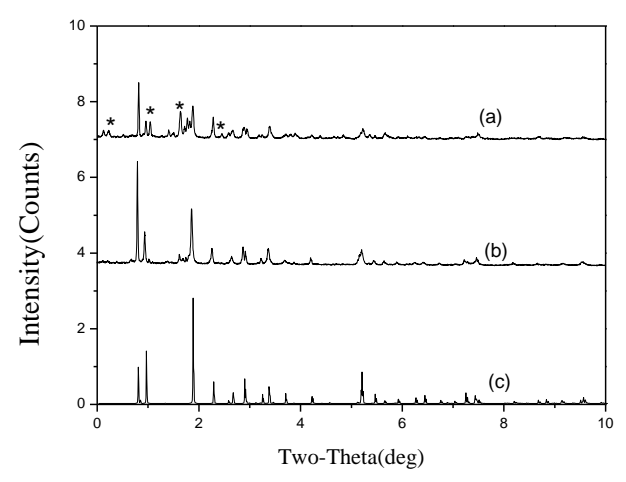

Fig. 1. XRD pattern of $\mathrm{BaSi}_{2} \mathrm{O}_{2} \mathrm{~N}_{2}: \mathrm{Eu}^{2+}(4 \mathrm{~mol} \%)$ by different preparation methods (a) solid-state reaction method (b) precursor method (c) Calculated XRD pattern of $\mathrm{BaSi}_{2} \mathrm{O}_{2} \mathrm{~N}_{2}$

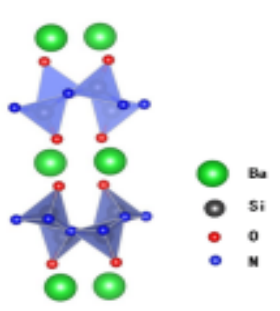

(a)

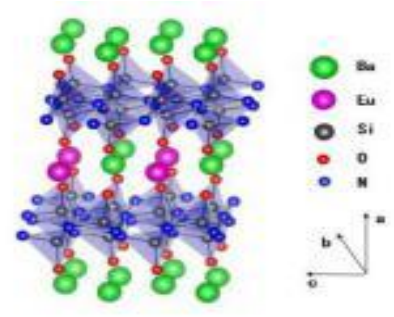

(b)

Fig.2.The crystal structure of $\mathrm{BaSi}_{2} \mathrm{O}_{2} \mathrm{~N}_{2}$ (a) and $\mathrm{Ba}_{1-\mathrm{x}} \mathrm{Si}_{2} \mathrm{O}_{2} \mathrm{~N}_{2}: \mathrm{XEu}^{2+}$ (b) 
The crystal structure of $\mathrm{BaSi}_{2} \mathrm{O}_{2} \mathrm{~N}_{2}$ is depicted in Fig. 2 (a). In the structure of $\mathrm{BaSi}_{2} \mathrm{O}_{2} \mathrm{~N}_{2}$, the $\mathrm{Eu}^{2+}$ ions are expected to substitute the $\mathrm{Ba}^{2+}$ ion sites in the $\mathrm{Ba}_{1-\mathrm{x}} \mathrm{Si}_{2} \mathrm{O}_{2} \mathrm{~N}_{2}: \mathrm{xEu}^{2+}$ crystal structure. The crystal structure of $\mathrm{Ba}_{1-\mathrm{x}} \mathrm{Si}_{2} \mathrm{O}_{2} \mathrm{~N}_{2}: \mathrm{xEu}^{2+}$ is schematically depicted in Fig. 2 (b).

The PL conversion performance of as-prepared $\mathrm{BaSi}_{2} \mathrm{O}_{2} \mathrm{~N}_{2}: \mathrm{Eu}^{2+}$ phosphors was investigated under excitation of $330 \mathrm{~nm}$, as shown in Fig.3. The sample prepared by the precursor method shows higher luminescence intensity than the sample prepared by the conventional method, though they show the same peak wavelength at $498 \mathrm{~nm}$. These results suggest that the intermediate phase degrades crystallinity and decreases luminescence efficiency. This improvement in the luminescence efficiency can also be realized by phase purification as shown in Fig. 1.

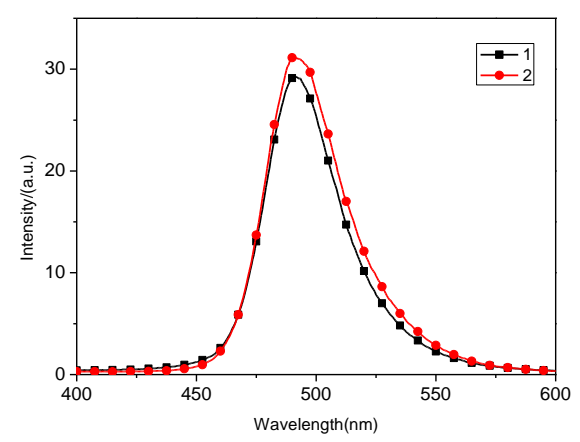

Fig. 3.The emission intensity comparison of $\mathrm{BaSi}_{2} \mathrm{O}_{2} \mathrm{~N}_{2}: \mathrm{Eu}^{2+}$

(1) solid-state reaction method (2) precursor method

Fig. 4 shows the XRD patterns of samples with various doping concentration ranged from $0 \%$ to $8 \%$. In the Fig. 4, the peaks of these diffractograms matched fairly well with the calculated patterns of $\mathrm{BaSi}_{2} \mathrm{O}_{2} \mathrm{~N}_{2}$ and an obviously increase of the main peak intensity of these impurity phases when doping concentration is $4 \%$, indicating that the content of these impurity phases increased. There is negligible influence of the substitution of $\mathrm{Eu}^{2+}$ ions on the crystalline structure of the host lattice of $\mathrm{BaSi}_{2} \mathrm{O}_{2} \mathrm{~N}_{2}$. Besides, the XRD diffraction peak moved towards to long wavelength with increasing $\mathrm{X}$ value. The $\mathrm{Eu}^{2+}$ will replace the position of $\mathrm{Ba}^{2+}$ in the doping process and the lattice of $\mathrm{BaSi}_{2} \mathrm{O}_{2} \mathrm{~N}_{2}$ will shrink when the $\mathrm{Ba}^{2+}$ is replaced by $\mathrm{Eu}^{2+}$ because of the radium of $\mathrm{Eu}^{2+}(1.12 \AA)$ is less than $\mathrm{Ba}^{2+}$ (1.35 $\AA$ ). The decrease of the spacing reflected in XRD spectrum is the diffraction peak moves to the big angle. This is not only shows the $\mathrm{Eu}^{2+}$ adds in the $\mathrm{BaSi}_{2} \mathrm{O}_{2} \mathrm{~N}_{2}$ lattice successfully, also proved that $\mathrm{Eu}^{2+}$ replace the position of $\mathrm{Ba}^{2+}$ in the $\mathrm{BaSi}_{2} \mathrm{O}_{2} \mathrm{~N}_{2}$ crystal lattice.

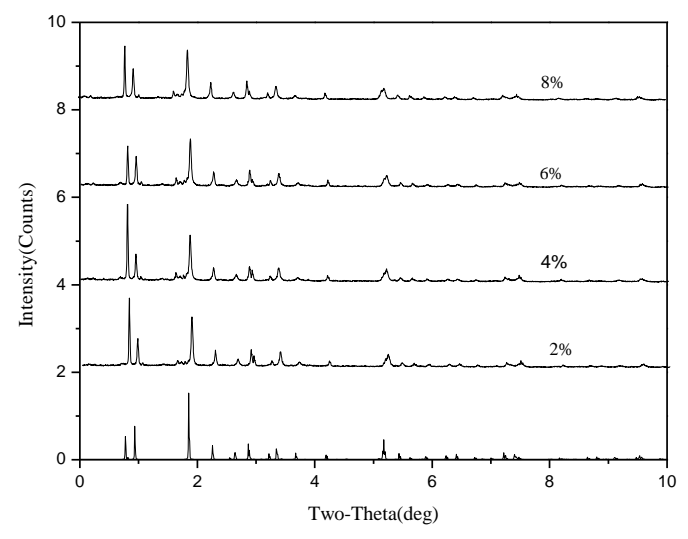

Fig. 4. XRD pattern of $\mathrm{Ba}_{1-\mathrm{x}} \mathrm{Eu}_{\mathrm{x}} \mathrm{Si}_{2} \mathrm{O}_{2} \mathrm{~N}_{2}(0 \leqslant \mathrm{x} \leqslant 0.08)$ phosphor samples prepared by precursor method

Fig. 5 shows emission spectra of samples with various doping concentration ranged from $0 \%$ to $8 \%$. The $\mathrm{BaSi}_{2} \mathrm{O}_{2} \mathrm{~N}_{2}: \mathrm{Eu}^{2+}$ phosphors show an emission band peaked at $498 \mathrm{~nm}$ for varied $\mathrm{Eu}^{2+}$ 
concentration, which is attributed to the $4 f^{6} 5 d^{1}-4 f^{7}$ transition of the doped $\mathrm{Eu}^{2+}$ ions. The emission intensity increased with $x$ value and shows the maximum at $x=0.04$. This is because that the phosphor absorbs more photon with the increasing of luminescence center concentration. The emission intensity declines gradually when the concentration of $\mathrm{Eu}^{2+}$ beyond $\mathrm{x}=0.04$ attributed to the concentration quenching effect. The fact that the emission bands shift to the longer wavelength region with increasing $\mathrm{Eu}^{2+}$ concentration is ascribed to the possible reason that the higher $\mathrm{Eu}^{2+}$ concentration lowers the emission energy ${ }^{[16]}$. Concentration quenching of luminescence becomes effective when $\mathrm{Eu}^{2+}$ contents surpassing $4 \%$ because the distance between $\mathrm{Eu}^{2+}$ ions becomes smaller, which leads to energy transfer between $\mathrm{Eu}^{2+}$ centers. The energy of $\mathrm{Eu}^{2+}$ converted to thermal vibration in a radiation way after absorbed by surrounding $\mathrm{Eu}^{2+}$ ions. Thus, The energy transfer between $\mathrm{Eu}^{2+}$ and self absorption in the high concentration sample caused the concentration quenching, made the emission intensity decreased.

The emission peak also has obvious red shift in the emission spectrum, which is due to the lattice contraction caused by the doping of $\mathrm{Eu}^{2+}$. In the higher concentration of $\mathrm{Eu}^{2+}$, more $\mathrm{Eu}^{2+}$ ions would substitute $\mathrm{Ba}^{2+}$ sites and the crystal lattice shrunk. The lattice shrunk will shorten the distance between $\mathrm{Eu}^{2+}$ and ligand $\mathrm{O}$ and $\mathrm{N}$ atoms, enhanced the electronic cloud expansion effect of center glow ions $\left(\mathrm{Eu}^{2+}\right)$, then the $5 \mathrm{~d}$ level will division, reduce the energy gap between 5 and 4 level, made the emission red shift.

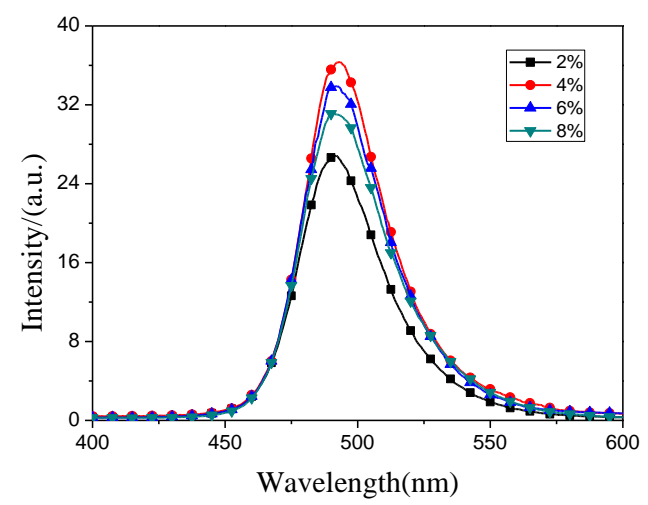

Fig. 5. The emission spectra of $\mathrm{Ba}_{1-\mathrm{x}} \mathrm{Eu}_{\mathrm{x}} \mathrm{Si}_{2} \mathrm{O}_{2} \mathrm{~N}_{2}(0 \leqslant \mathrm{x} \leqslant 0.08)$ phosphor samples prepared by precursor method

The influence of firing temperature on the luminescence properties of $\mathrm{BaSi}_{2} \mathrm{O}_{2} \mathrm{~N}_{2}: \mathrm{Eu}^{2+}(4 \%)$ is shown in Fig. 6. The positions of the emission peak are slightly influenced by temperature. The emission intensity increased gradually with increasing of temperature and reached the maximum when fired at $1400^{\circ} \mathrm{C}{ }^{\circ} \mathrm{C}$. The emission intensity declines gradually when the concentration of $\mathrm{Eu}^{2+}$ beyond $\mathrm{x}=0.04$ attributed to the thermal quenching. With increasing firing temperature, the reaction process is promoted, whicn makes $\mathrm{Eu}^{2+}$ fully occupy the $\mathrm{Ba}^{2+}$ ion sites in the $\mathrm{BaSi}_{2} \mathrm{O}_{2} \mathrm{~N}_{2}$ crystal structure, forming a phase closer to $\mathrm{Ba}_{0.96} \mathrm{Si}_{2} \mathrm{O}_{2} \mathrm{~N}_{2}: 0.04 \mathrm{Eu}^{2+}$. In the higher temperature, more $\mathrm{Eu}^{2+}$ ions would substitute $\mathrm{Ba}^{2+}$ sites and the crystal lattice shrunk, which leads to emission intensity decrease.

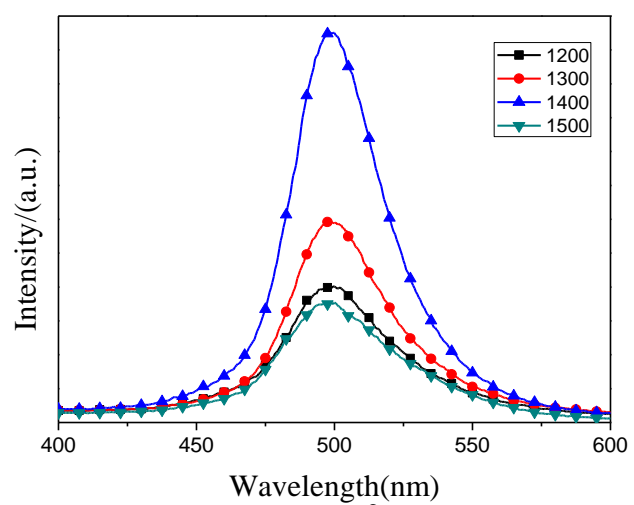

Fig. 6. The emission spectra of $\mathrm{BaSi}_{2} \mathrm{O}_{2} \mathrm{~N}_{2}: \mathrm{Eu}^{2+}(4 \%)$ fired at different temperature prepared by precursor method 
Fig. 7 shows the SEM images of $\mathrm{BaSi}_{2} \mathrm{O}_{2} \mathrm{~N}_{2}: \mathrm{Eu}^{2+}$ powders prepared by different methods. It is observed that some of the powders are agglomerated into irregular morphologies in Fig. 7(a). On the contrary, the phosphor powers prepared by precursor method(b) have regular morphology and uniform size. The average size of the powders is in the range of $2-8 \mu \mathrm{m}$, in line with the requirements of phosphors for white LED. The result indicating that the precursor method can improve the crystallinity of $\mathrm{BaSi}_{2} \mathrm{O}_{2} \mathrm{~N}_{2}$.

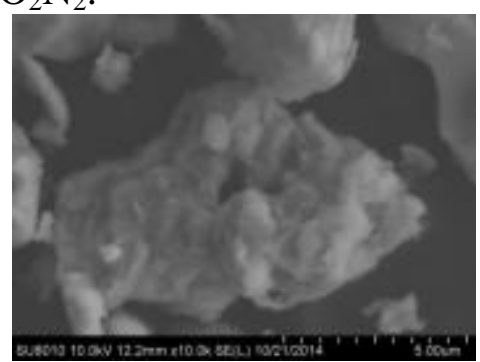

(a)

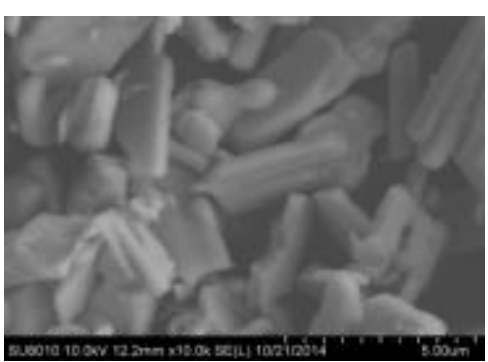

(b)

Fig. 7. The SEM image of $\mathrm{Ba}_{0.96} \mathrm{Eu}_{0.04} \mathrm{Si}_{2} \mathrm{O}_{2} \mathrm{~N}_{2}$ phosphors fired at $1400{ }^{\circ} \mathrm{C}{ }^{\circ} \mathrm{C}$ by different methods (a) solid-state reaction method (b) precursor method

\section{Summary}

The bluish-green $\mathrm{BaSi}_{2} \mathrm{O}_{2} \mathrm{~N}_{2}: \mathrm{Eu}^{2+}$ phosphor was successfully synthesized by a method using $\mathrm{Ba}_{2} \mathrm{SiO}_{4}$ as a precursor. The crystal structures and luminescence characteristics were investigated. Almost single-phase $\mathrm{BaSi}_{2} \mathrm{O}_{2} \mathrm{~N}_{2}: \mathrm{Eu}^{2+}$ was obtained by the precursor method. Under $330 \mathrm{~nm}$ excitation, the emission spectra shows the most high intensity at $498 \mathrm{~nm}$ and the intensity is higher than that of the phosphor prepared by conventional solid-state reaction method. Indicates that precursor method provides increased crystallinity and luminescence efficiency compared with the conventional solid-state reaction method. These excellent luminescence properties suggested that $\mathrm{BaSi}_{2} \mathrm{O}_{2} \mathrm{~N}_{2}: \mathrm{Eu}^{2+}$ is an excellent phosphor for white LEDs.

\section{Acknowledgements}

This work was supported by National Natural Science Foundation of China (No. 61177050, 61405183 and 61575182), Key Program of Natural Science Foundation of Zhejiang Province (No.Z1110222), Natural Science Foundation of Zhejiang Province (No.Y16F050012), Zhejiang Xinmiao Talent Project (No.2014R409053) and Application Research Program of Commonweal Technology of Zhejiang Province (No. 2015C31102) .

\section{References}

[1] Schlotter P, Baur J, Hielscher C, et al. Fabrication and characterization of GaN/InGaN/AlGaN double heterostructure LEDs and their application in luminescence conversion LEDs. Materials Science and Engineering: B, 1999, 59(1):390-394.

[2] Yang L, Xu X, Hao L, et al. Optimization mechanism of $\mathrm{CaSi}_{2} \mathrm{O}_{2} \mathrm{~N}_{2}: \mathrm{Eu}^{2+}$ phosphor by $\mathrm{La}^{3+}$ ion doping. Journal of Physics D: Applied Physics, 2011, 44(35):355403.

[3] Jang H S, Im W B, Lee D C, et al. Enhancement of red spectral emission intensity of $\mathrm{Y}_{3} \mathrm{Al}_{5} \mathrm{O}_{12}$ : $\mathrm{Ce}^{3+}$ phosphor via Pr codoping and $\mathrm{Tb}$ substitution for the application to white LEDs. Journal of luminescence, 2007, 126(2): 371-377.

[4] $\mathrm{Yu} \mathrm{X}$, Zhang L, Xu X, et al. Development of a single-phased $\mathrm{Ca}_{3} \mathrm{SnSi}_{2} \mathrm{O}_{9}$ : $\mathrm{Bi}^{3+}, \mathrm{Dy}^{3+}, \mathrm{Eu}^{3+}$ phosphor with tri-colors for white light-emitting diode. Journal of luminescence, 2014, 145 (Complete): 114-118. 
[5] Oeckler O, Stadler F, Schnick W. Real structure investigations on oxonitridosilicates $\mathrm{MSi}_{2} \mathrm{O}_{2} \mathrm{~N}_{2}$ (M=Ca, Sr, Ba, Eu). Acta Cryst, 2006, 62: s202.

[6] Y.Q.Li, A.C.A.Delsing, G.deWith, and H.T.Hintzen, Luminescence Properties of $\mathrm{Eu}^{2+}$-Activated Alkaline-Earth Silicon-Oxynitride $\mathrm{MSi}_{2} \mathrm{O}_{2}-\mathrm{\delta N}_{2+2 / 3 \delta}(\mathrm{M}=\mathrm{Ca}, \mathrm{Sr}, \mathrm{Ba})$ : A Promising Class of Novel LED Conversion Phosphors, Chem. Mater., 17 [12] 3242-8 (2005).

[7] V. Bachmann, C. Ronda, O. Oeckler,et al. Color Point Tuning for (Sr,Ca,Ba)Si2O2N2:Eu ${ }^{2+}$ for White Light LEDs, Chem. Mater.,21 [2] 316-25 (2009).

[8] Tuecks A, Schmidt P, Schreinemacher B, et al. Investigations on $\mathrm{Eu}^{2+}$-Doped $\mathrm{MSi}_{2} \mathrm{O}_{2} \mathrm{~N}_{2}$ LED Phosphors. Meeting Abstracts. The Electrochemical Society. 2008: 3200-3200.

[9] Hirosaki N, Xie R-J, Kimoto K, et al. Characterization and properties of green-emitting $\beta$-SiAlON: $\mathrm{Eu}^{2+}$ powder phosphors for white light-emitting diodes. Applied Physics Letters, 2005, 86(21): 211905.

[10] Li H L, Xie R J, Hirosaki N, et al. Synthesis and Luminescence Properties of Orange-Red-Emitting $\mathrm{M}_{2} \mathrm{Si}_{5} \mathrm{~N}_{8}: \mathrm{Eu}^{2+}(\mathrm{M}=\mathrm{Ca}, \mathrm{Sr}$, Ba) Light-Emitting Diode Conversion Phosphors by a Simple Nitridation of $\mathrm{MSi}_{2}$. International Journal of Applied Ceramic Technology, 2009, 6(4): 459-464.

[11] Zeuner M, Hintze F, Schnick W. Low temperature precursor route for highly efficient spherically shaped LED-phosphors $\mathrm{M}_{2} \mathrm{Si}_{5} \mathrm{~N}_{8}: \mathrm{Eu}^{2+}(\mathrm{M}=\mathrm{Eu}, \mathrm{Sr}, \mathrm{Ba})$. Chemistry of materials, 2008, 21(2): 336-342.

[12] Zeuner M, Schmidt P J, Schnick W. One-pot synthesis of single-source precursors for nanocrystalline LED phosphors $\mathrm{M}_{2} \mathrm{Si}_{5} \mathrm{~N}_{8}: \mathrm{Eu}^{2+}(\mathrm{M}=\mathrm{Sr}$, Ba). Chemistry of materials, 2009, 21(12): 2467-2473.

[13] B.G. Yun,Y.Miyamoto, H. Yamamoto, Luminescence properties of $\left(\mathrm{Sr}_{1-\mathrm{u}} \mathrm{Ba}_{\mathrm{u}}\right) \mathrm{Si}_{2} \mathrm{O}_{2} \mathrm{~N}_{2}: \mathrm{Eu}^{2+}$, yellow or orange phosphors for white LEDs, synthesized with $\left(\mathrm{Sr}_{1-\mathrm{u}} \mathrm{Ba}_{\mathrm{u}}\right) \mathrm{SiO}_{4}: \mathrm{Eu}^{2+}$ as a precursor, J. Electrochem. Soc. 154 (2007) 320-325.

[14] B.G. Yun, T. Horikawa, H. Hanzawa, et al. Preparation and luminescence properties of single-phase $\mathrm{BaSi}_{2} \mathrm{O}_{2} \mathrm{~N}_{2}: \mathrm{Eu}^{2+}$, a bluish-green phosphor for white light-emitting diodes, J. Electrochem. Soc. 157 (2010) 320-325.

[15] B.G. Yun, T. Horikawa, H. Hanzawa, et al. Preparation and luminescence properties of single-phase $\mathrm{BaSi}_{2} \mathrm{O}_{2} \mathrm{~N}_{2}: \mathrm{Eu}^{2+}$, a bluish-green phosphor for white light-emitting diodes, J. Electrochem. Soc. 157 (2010) 364-370.

[16] R.J. Xie, N. Hirosaki, K. Sakuma, Y. Yamamoto, M. Mitomo, Eu ${ }^{2+}$-doped Ca-a-SiAlON: a yellow phosphor for white light-emitting dioeds, Appl. Phys. Lett. 84 (2004) 5404-5406. 